\title{
From Essence to Metaphysical Modality?
}

\author{
Harold W. Noonan ${ }^{1}$
}

Received: 14 July 2020 / Accepted: 4 November 2020/Published online: 22 November 2020

(C) The Author(s) 2020

\begin{abstract}
How can we acquire knowledge of metaphysical modality? How can someone come to know that he could have been elsewhere right now, or an accountant rather than a philosophy teacher, but could not have been a turnip? Jago proposes an account of a route to knowledge of the way things could have been and must be. He argues that we can move to knowledge of metaphysical modality from knowledge about essence. Curtis rejects Jago's explanation. It cannot, he argues, explain our knowledge of de re necessity. We agree. But there is more to be said. To give an account of our knowledge of metaphysical necessity is part of the task Jago set himself. But another part is to give an account of the knowledge of the (non-actual) possibilities accorded to particular objects. And prior to both what is needed, and something Jago attempts to supply, is an account of how ordinary knowers can come to have knowledge of an individual's essential properties. We argue that Jago's accounts of both these additional matters are also unsatisfactory. This is important because the thought that our knowledge of metaphysical modality has its source in our knowledge of essence is currently an attractive one and Jago has set out very clearly what must be done to justify the thought. The flaws in his proposal thus indicate the work needed if the attractive thought is to be accepted.
\end{abstract}

Keywords Essence $\cdot$ Necessity $\cdot$ Fine $\cdot$ Lowe $\cdot$ Sortal concept

\section{Introduction}

The Aristotelian concept of essence, of 'what it is to be', and the link, if any, between that concept and the modal concepts of necessity and possibility were core topics of metaphysical discussion in the centuries that followed its introduction. Aristotle himself favoured a so-called 'definitional' account of essence according to which the concept of essence can be specified independently of de re modal notions,

Harold W. Noonan

Harold.noonan@nottingham.ac.uk

Extended author information available on the last page of the article 
although he saw a link between modal concepts and concepts closely related to that of essence, in the Topics defining the notion of an accidental property, for example, in terms of a property that might or might not belong to an object (cf. Fine 1994: 2)). The issue of the link between essence and modality persisted beyond antiquity and was discussed at length by Avicenna and the scholastic philosophers in the middle ages (e.g. Boethius, Aquinas, Ockham) where the question of whether essence can be separated from existence took center stage, with modal notions (and in particular the distinction between what is actual and what is merely possible) playing key roles in the debate. (See, e.g. Witt 2011; Normore 2012) And in modernity too the link was widely discussed, with both Locke and Mill, to give just two examples, taking positions on the matter. (Locke 1975, Bk. 3, Chap. 3; Mill 1843, Bk. 1, Chap. vi). This, however, ceased to be so in the mid-twentieth century, when the concept of essence was jettisoned, at least in the Anglo-American philosophical circles influenced by the logical empiricists, as a piece of metaphysical nonsense. Talk of essence soon reestablished itself, however, with the development of quantified modal logic and the revival of interest in de re modality following the work of Marcus (collected in Marcus 1995) and Kripke (1972, 1980). But the account of essence which was the standard from the 1950s to 1994 was a modal account, according to which one can specify the essential properties an individual has in terms of its possession of de re necessary properties. However, since then, largely due to the seminal work of Kit Fine $(1994,1995 a, 1995 b, 2000)$ and that of Jonathan Lowe (1997, 2007, 2008, 2011, 2012a, 2012b), there has been a resurgence of interest in giving a broadly Aristotelian account of essence according to which we can specify the essential properties an individual has independently of its de re necessary properties, but in a way that nonetheless explains why its essential properties are also de re necessary ones. ${ }^{1}$ Here is how Mark Jago, a recent advocate of the view, has summed it up:

Here is a rough outline of the idea. If something is necessarily such that A, then something or some things are essentially such that A. That necessity obtains because those things are essentially such that A... [E]ssence is the source or basis of necessity. The simplest case is when an object is necessarily $\mathrm{F}$ because it itself is essentially F. It is necessary that I am human because being human is part of my essence. (Jago 2018: 6)

The neo-Aristotelian account appeals to the idea that an essential property is part of an object's 'real definition' or part of 'what an object is', understood in some metaphysically significant Aristotelian sense (see, e.g., Fine (1994), Lowe (2008), Gorman (2005)). As we will put it, neo-Aristotelian essentialists hold that a property $\mathrm{F}$ is an essential property of $\mathrm{x}$ if specifying $\mathrm{F}$ gives a correct answer to the Aristotelian 'what is $\mathrm{x}$ ?' question.

Now, it should be clear from the above that a crucial claim accepted by neoAristotelian essentialists is the following one:

\footnotetext{
1 Of course, Quine rejected what he called 'Aristotelian essentialism' in his battle against quantified modal logic (e.g., in his 1953 and 1961) and unfortunately for him lived long enough to see it thrive in the aftermath of the Kripkean revolution. But what he and Kripke (1972) debated was a notion of essence defined in terms of de re necessity, i.e. the notion given by the modal account of essence.
} 
Essence-Necessity Link (E-N): If $\mathrm{x}$ is essentially $\mathrm{F}$, then $\mathrm{x}$ is necessarily $\mathrm{F}$ if it exists.

And it should also be clear that if neo-Aristotelian essentialists are to achieve their aim of explaining de re necessity in terms of essence, they must provide us with at least some reason for believing E-N to be true.

In the recent literature on essence the question whether this can be done has been pressed by a number of authors (Casullo 2020; Leech 2018; Mackie 2020; Noonan 2018; Romero 2019).

Jago defends E-N. In fact, he defends it as a conceptual truth. He also gives an account of how ordinary knowers can come to know an individual's essential properties. And, on the basis of the thesis that E-N is a conceptual truth, he argues that knowers can move from knowledge of individuals' essential properties to knowledge of their metaphysically necessary and non-actual but possible properties. That is, Jago proposes an essentialist account of a route to knowledge of the way things must be and could have been.

We argue that Jago's essentialist account of our knowledge of de re metaphysical modality fails. He does not succeed in explaining how knowledge of de re metaphysical ncecessity can be acquired on the basis of knowledge of the essential properties of individuals. Nor does he succeed in explaining how knowledge of nonactual de re possibility can be acquired on this basis. Finally, he does not succeed in explaining how ordinary knowers can come to have knowledge of an individual's essential properties. This is important because the thought that our knowledge of metaphysical modality has its source in our knowledge of essence is currently an attractive one and Jago has set out very clearly what has to be done to justify the thought. The flaws in his proposal thus indicate the work needed if the attractive thought is to be accepted.

We give the arguments for the contentions just made after first outlining the structure of Jago's paper and then filling out the details of the essentialist position he adopts (inspired by Fine).

\section{Jago's Paper}

Jago's paper has four parts. First, he explains two accounts of modal epistemology he rejects: the conceivability account inspired by Hume and the counterfactual knowledge account put forward by Williamson (2007). He criticizes these as a way of providing motivation for the Finean account he defends. Next he gives an account of the Finean theory that facts about metaphysical modality are grounded in facts about essence, clarifying the modifications he wishes to make. He defends the theory from a criticism by Wildman (2018), but his main argument for it is an argument for the conceptual truth of E-N, considered below. The rest of the paper is devoted to the exposition and defence of the essentialist theory of our epistemic access to modality outlined in our Introduction. The argument that we can have knowledge of an individual's essence draws on considerations about how reference, in particular reference to coincident material objects, is possible. And the argument 
that knowledge of metaphysical modality can be arrived at via knowledge of essence is then based on the contention that E-N is a conceptual truth.

\section{Essentialism}

The essentialist theory of modality Jago endorses derives from Fine. In his seminal paper (1994) Fine gives conclusive counter-examples to the straightforward identification of essential properties with necessary ones. His most famous example is the following, in his own words:

Consider, then, Socrates and the set whose sole member is Socrates. It is then necessary, according to standard views within modal set theory, that Socrates belongs to singleton Socrates if he exists; for, necessarily, the singleton exists if Socrates exists and, necessarily, Socrates belongs to singleton Socrates if both Socrates and the singleton exist. It therefore follows according to the modal criterion that Socrates essentially belongs to singleton Socrates.... But, intuitively, this is not so. It is no part of the essence of Socrates to belong to the singleton. (1994: 4-5)

Similarly, Fine argues, necessarily if Socrates exists then $2+2=4$. There is no world in which Socrates exists and $2+2$ does not equal 4 because it is true in all worlds that $2+2=4$. However, it does not seem to be part of the essence of Socrates that $2+2=4$.

One response to Fine's examples has been to attempt to define essential properties as a sub-species of necessary properties (see Leech (2018): section 3 for a survey). But this is not Fine's response. Rather he says:

[F]ar from viewing essence as a special case of metaphysical necessity, we should view metaphysical necessity as a special case of essence. For each class of objects, be they concepts or individuals or entities of some other kind, will give rise to its own domain of metaphysically necessary truths, the truths which flow from the nature of the objects in question. The metaphysically necessary truths can then be identified with the propositions which are true in virtue of the nature of all objects whatever. (Fine 1994: 9)

In the simplest case, as noted by Jago in the first quotation above, an object is necessarily $\mathrm{F}$ because it is essentially $\mathrm{F}$, it is part of its essence that it is $\mathrm{F}$. That is why Socrates is necessarily human. But the metaphysical necessity that if Socrates exists then $2+2=4$ does not obtain in virtue of the essence of Socrates. It is metaphysically necessary that if Socrates exists $2+2=4$ in virtue of the essences of 2 and 4 and perhaps addition. Again, Socrates is necessarily a member of singleton Socrates not because it is part of his essence alone to be so, but in virtue of the essence of the singleton.

Thus it is not the case that whenever something is necessarily $\mathrm{F}$ it is essentially $\mathrm{F}$, but in the simplest case it is. And the truth of E-N is part of the Finean position: if is part of the essence of $\mathrm{x}$ that it is $\mathrm{F}$ then $\mathrm{x}$ is necessarily $\mathrm{F}$ since the truth that $\mathrm{x}$ is $\mathrm{F}$ 
'flows from' the nature of x. Jago's claim, as we have noted, is that this is not only true but conceptually true.

\section{Knowledge of de re Necessities}

We now turn to our critique of Jago's position. We begin with a criticism from Curtis (2019) of Jago's claim that E-N is a conceptual truth and thus implicitly available to ordinary knowers. Rather, Jago says, it is merely a theoretical component of Fine's theory of essence, which ordinary knowers are not acquainted with.

Jago recognizes the importance of the contention that E-N is a conceptual truth for his position. He writes, it is part of [the standard] concepts of essence and necessity that whoever possesses these concepts and knows that $\mathrm{x}$ is essentially $\mathrm{F}$ thereby knows, or is in a position to come to know by reflection, that it is necessary that ' $\mathrm{x}$ is F' (Jago 2018: 214).

But Curtis asks, how can a link between an individual's essential properties and his de re necessary properties be a conceptual one? If essence is defined in terms of metaphysical necessity (so that being essentially $\mathrm{F}$ is being necessarily $\mathrm{F}$ and ...) this could be so, but this is in direct opposition to Fine's theory of essence. We could also understand the link between essence and de re necessity as a conceptual one, we will add, if we thought of being essentially $\mathrm{F}$ as a way of being necessarily $\mathrm{F}$ (as being red is a special way of being coloured though being red cannot be defined as being coloured and ...). But again this is what a Finean cannot say (Fine says, recall, that according to the neo-Aristotelian essentialist point of view, 'far from viewing essence as a special case of metaphysical necessity, we should view metaphysical necessity as a special case of essence' (1994: 9)).

But otherwise how can the link between essence and de re necessity be understood as conceptual? Curtis writes, 'Put in terms of possible worlds E-N tells us, for example, that if being human is part of an individual's essence in the actual world, then that very being possesses being human in every world in which it exists. Quite how this can be a conceptual truth is utterly perplexing' (Curtis 2019: 3).

Curtis acknowledges a conceptual link between the notion of essence and one notion of necessity, the notion of de dicto necessity. It is, for example, plausible that if electrons are essentially negatively charged (i.e., if that is part of just what it is to be an electron) then it is a conceptual truth that 'necessarily, for all $\mathrm{x}$, if $\mathrm{x}$ is an electron, then $x$ is negatively charged'. Similarly, if bachelors are essentially men (males) (i.e., if it is part of what it is to be a bachelor to be a man) then it is a conceptual truth that necessarily, for all $\mathrm{x}$, if $\mathrm{x}$ is a bachelor, then $\mathrm{x}$ is a man. But these are merely de dicto necessities. What Jago needs an argument for is, for example, the proposition that it is a conceptual truth that if $\mathrm{x}$ is essentially an electron then $\mathrm{x}$ is necessarily negatively charged. But such a conceptual link between essence and de necessity is simply not supported by these considerations in support of such a link between essence and de dicto necessity. 
However, it is precisely these considerations that Jago appeals to in support of the conceptual link between essence and necessity, as Curtis notes. For example, Jago writes:

[T]he concept of necessity is linked to the concept of essence. There is evidence for the link in everyday usage.... For example, having been asked why ... bachelors are always men, one may reply: ... Bachelors have to be men. That's part of the nature of being a bachelor.... That the explanations are natural suggests the link from essence to necessity is embedded in everyday conceptual schemes. (2018: 15)

The link between essence and de dicto necessity may indeed be so embedded, but what Jago needs to be embedded is a link between essence (nature, what it is to be) and de re necessity. Without that his essentialist account of our knowledge of de re necessities (e.g., that I could not have been a turnip) fails.

\section{Knowledge of de re Possibility}

If it fails, however, so also we now argue does his account of our knowledge of de re possibility. We could have now been in Germany (we are not). We could have been accountants (we are not). How can we know these things? Jago argues that we can know them via knowledge of what is inessential to us (2018: 12), and we can know this because we can know the kind (sort) of thing we are (human beings). Speaking of knowledge of your de re possibilities he writes (2018: 15):

I know that I could have been where you are right now and you here. My belief is based on my understanding of the kinds of things that you and I (and here and there) are. You and I are both human beings, for whom each specific location is inessential. My front room is a very ordinary room in an ordinary location. In particular, nothing about what makes it the place it is excludes your being here. I know all that. So I know that nothing in the essences of those entities excludes your being here. I may then infer that you could have been here. If I do, the inference will preserve knowledge and so I will come to know that you could have been here.

Mutatis mutandis, we know that we could have been accountants. How? Well, we know that we are human beinsg, for whom each specific life path is inessential. So we know that nothing in our essences excludes being accountants. We infer thatwe could have been accountants.

Recall now that according to Jago we move from knowledge about essence to knowledge about metaphysical modality. So the idea is that we can move from knowledge that any life path we in fact follow is inessential to the de re possibility of another one: for example, from the inessentiality of being here to the possibility of being elsewhere, or from the inessentiality of being philosophy teachers to the possibility of not being philosophy teachers, but, for example, accountants. But, importantly, it appears that there is a more direct explanation available of our knowledge that we could have been accountants. It is a conceptual truth, one can 
say, that if something is a human being it could have had a different life path from the one it has ('necessarily, for any $\mathrm{x}$, if $\mathrm{x}$ is a human being and $\mathrm{x}$ is a philosopher then possibly, $\mathrm{x}$ is not a philosopher' is conceptually true). Thus, from knowing that someone is a human being one can infer that he could have followed some other life path (for example, become an accountant). For us to know this and to make the inference it suffices that we have the concepts of a human being, a philosopher and de re modality. If we are allowed to appeal in the explanation of our knowledge of de re possibility to conceptual truths linking concepts of sortal kinds, like human being, to the concept of essence, then we can more directly appeal to such truths linking these concepts to the concept of de re possibility/necessity. ${ }^{2}$ Jago's appeal to essence thus appears to be redundant here. Indeed, it seems obvious that the inference he is making goes the other way. When we accept his claim that it is an inessential property of you that you are where you in fact are (and could have been here) why do we accept this? Because we think that you need not have been where you are (unlike, for example, a lake). ${ }^{3}$

\section{Knowledge of Essences}

So far we have objected to Jago's attempt to show how ordinary knowers can move from knowledge of essence to knowledge of metaphysical modality. We now turn to his account of how ordinary knowers can come to knowledge of an individual's essential properties itself.

Jago's starting point is reference to material objects, and specifically, reference to sometime coincident material objects, like the statue and the clay, or the painting and the coincident collection of molecules (Jago 2018: 9). How can we refer to the statue which is coincident with the piece of clay? What secures reference in this case, he says, entirely convincingly, is specification of a location plus a specification which distinguishes the coincident objects in that location. We single out the statue as the statue in the location. So our belief that the object we are speaking of is a statue (if it exists) is safe (Jago 2018: 12). If we are successful in referring to anything it cannot fail to be a statue. But Jago argues, when we conceptualise something as of sort F we typically think of it as being essentially F. So we not only think that the thing we are picking out (the statue) is a statue. We also believe that it is essentially a statue. And just as our belief that it is a statue (if it exists) is safe (we

\footnotetext{
${ }^{2}$ Of course, either appeal can be disputed, e.g., by Quinean sceptics about modality and essence and those who follow Lewis in thinking that modal predication is inconstant. Their position will be that the only objective knowledge of modality we have, is at most, knowledge of de dicto modality. We know for example, that it is possible that something is a human being and not a philosopher. So how do we know that Lewis need not have been a philosopher, but could have been, for example, an accountant? The Lewisean story is this. To know this is to know Lewis has a contextually salient counterpart in some (other) possible world who is not a philosopher but an accountant, someone who resembles him in contextually salient ways. But we do, in fact, know this, because we know that that there are many (similarly educated, intelligent etc.) actual men who are accountants. This is the easy case for a Lewisean; knowledge that he could have been an accountant who is also a lion tamer, or a cross-dressing lumberjack (assuming there are actually none) is harder.

3 Jago (2018: 13) mentions Hirsch's (1976) 'incars' as an example of things whose particular location is essential to them; lakes seem a more familiar example.
} 
would not be referring to it unless it was) so our belief that it is essentially a statue is safe (given what the essentialist thinks, that statues are essentially statues). So as a safe true belief it constitutes knowledge of an individual's essence.

This argument delivers less than appears. Let it be granted that we have a notion of what sort of thing a thing is such that knowing that something is a statue amounts to knowing what sort of thing it is (statue is a sortal concept). So if we believe that something is a statue we will believe, because we have this concept of a sort, both that it is a statue and that being a statue is the sort of thing it is. Then in the circumstances envisaged by Jago (of successful reference to one of two coincident entities) just as we know that it is a statue if it exists we know that being a statue is the sort of thing it is if it exists. Instead of describing what we know in this way we can speak instead of nature or essence (the neo-Aristotelian concept of essence is, of course, tightly linked to the notion of a sortal concept $)^{4}$ and so we can say that we know that the thing is a statue if it exists and its essence is to be a statue, or that we know that it is essentially a statue if it exists. But now the crucial question for Jago again becomes what the link is between this notion of essence, understood via the notion of a sort, and the notion of de re necessity. How is it to be established as a conceptual truth that if $\mathrm{x}$ is of sort $\mathrm{F}$ it is of de re necessity of sort F? Jago's idea is that in the circumstances he envisages appeal to a (substance) sortal property (being a statue) is necessary for identifying reference and thought about the thing possessing it. But even if this is so, and even if (to be still more concessive) in every situation in which it exists an object can only be identified and spoken about by appeal to the (substance) sortal property it possesses in that situation, it remains mysterious that the substance sortal property a thing in fact possesses (i.e., possesses in the actual world) must be one it necessarily possesses (i.e., possesses in any world in which it exists). Given that Kal-El is a human-like Kryptonian could he not have been (laws of copyright aside) a super-powered android or a hammer-wielding Norse god? Could Lewis's plastic dishpan (1986: 252) not have been a plastic toy duck (as it might have been if there had not been a last-minute change of production line in the factory)? If these things had been thus different they would still have been identifiable under sortal concepts, just different sortal concepts. If Jago's concept of essence is such that we can infer from the fact that something is a statue and statue is a sortal kind that it is essentially a statue all the interest of the paper shifts to the question whether there is a conceptual link between sortalhood and de re necessity. But if the concept of essence is understood to incorporate the link to de re necessity, his inference that if we know, for example, that something is a statue we can know that it is essentially a statue becomes problematic. What remains, like the frog peering up at us from the bottom of the beer mug, is still the question of the conceptual truth of E-N.

\footnotetext{
${ }^{4}$ Fine himself agrees with this and that the link is crucial to explaining knowledge of modality via knowledge of essence. In his (2005), after summarising his view that we must give a non-modal account of which properties are essential properties and explain modal properties in terms of them, he says (taking 'man' as his example): 'The only plausible non-modal definition of "man" is one that classifies the object under a sort; to be a man is to be an F (where this is the sort) differentiated in such and such a way. If we use only ordinary non-sortal properties in stating what a man is, then it is hard to see how the definition could have the required modal import' (Fine 2005: 348).
} 


\section{Conclusion}

That is the argument. We conclude that Jago has not provided an adequate account of how ordinary knowers can come to knowledge of metaphysical modality on the basis of knowledge of essence.

Open Access This article is licensed under a Creative Commons Attribution 4.0 International License, which permits use, sharing, adaptation, distribution and reproduction in any medium or format, as long as you give appropriate credit to the original author(s) and the source, provide a link to the Creative Commons licence, and indicate if changes were made. The images or other third party material in this article are included in the article's Creative Commons licence, unless indicated otherwise in a credit line to the material. If material is not included in the article's Creative Commons licence and your intended use is not permitted by statutory regulation or exceeds the permitted use, you will need to obtain permission directly from the copyright holder. To view a copy of this licence, visit http:// creativecommons.org/licenses/by/4.0/.

\section{References}

\section{Aristotle, Topics}

Casullo A (2020) Essence and explanation. Metaphysics 2:88-96

Curtis BL (2019) Can essence provide knowledge of metaphysical necessity? A reply to Jago. Philosophia 48:1-3. https://doi.org/10.1007/s11406-019-00116-1

Fine K (1994) Essence and modality. In: Tomberlin J (ed) Philosophical perspectives 8: Logic and language. Ridgeview Publishing Company, Atascadero, CA, pp 1-16

Fine K (1995a) Ontological dependence. Proc Aristot Soc 95:269-290

Fine K (1995b) Senses of essence. In: Sinnott-Armstrong W, Raffman D, Asher N (eds) Modality, morality, and belief: Essays in honor of Ruth Barcan Marcus. Cambridge University Press, Cambridge, pp 53-73

Fine K (2000) Semantics for the logic of essence. J Philos Log 29:543-584

Fine K (2005) Necessity and non-existence. In: Modality and tense: Philosophical papers. Oxford University Press, Oxford, pp 321-354

Gorman M (2005) The essential and the accidental. Ratio 18:276-289

Hirsch E (1976) Physical identity. Philos Rev 85(3):357-389

Jago M (2018) Knowing how things might have been. Synthese:1-19. https://doi.org/10.1007/s11229018-1869-6

Kripke S (1972) Naming and necessity. In: Davidson D, Harman G (eds) Semantics of natural language. Reidel, Dordrecht, pp 252-355

Kripke S (1980) Naming and Necessity. Basil Blackwell, Oxford. (Expanded monograph version of Kripke 1972)

Leech J (2018) Essence and mere necessity. R Inst Philos Suppl 82:309-332

Lewis D (1986) On the plurality of worlds. Blackwell, Oxford

Locke J (1975) An essay concerning human understanding. PH Nidditch (ed.). Oxford University Press, Oxford

Lowe EJ (1997) Objects and criteria of identity. In: Hale B, Wright C (eds) A companion to the philosophy of language. Blackwell, Oxford, pp 613-633

Lowe EJ (2007) Review of mackie, how things might have been. Mind 116:762-766

Lowe EJ (2008) Two notions of being: entity and essence. In: Le Poidevin R (ed) Being: developments in contemporary metaphysics: royal institute of philosophy supplement 62. Cambridge University Press, Cambridge, pp 23-48

Lowe EJ (2011) Locke on real essence and water as a natural kind: a qualified defence. Proc Aristot Soc $85: 1-19$ 
Lowe EJ (2012a) The probable simplicity of personal identity. In: Gasser G, Stefan M (eds) Personal identity: complex or simple? Cambridge University Press, Cambridge, pp 137-155

Lowe EJ (2012b) What is the source of our knowledge of modal truths? Mind 121:919-950

Mackie P (2020) Can metaphysical modality be based in essence? In: Dumitru M (ed) Metaphysics, meaning, and modality: themes from kit fine. Oxford University Press, Oxford, pp 247-264

Marcus R (1995) Modalities: philosophical essays. Oxford University Press, New York

Mill JS (1843) A system of logic, ratiocinative and inductive: being a connected view of the principles of evidence, and the methods of scientific investigation. Cambridge University Press, Cambridge

Noonan H (2018) The new aristotelian essentialists. Metaphysica 19:87-93

Normore C (2012) Ockham on being. In: Haaparanta L, Koskinen HJ (eds) Categories of being: essays on metaphysics and logic. Oxford University Press, Oxford, pp 78-98

Quine WVO (1953) Three grades of modal involvement. In: Proceedings of the XIth International Congress of Philosophy, Brussells, vol 14, North Holland Publishing Co., Amsterdam. Reprinted in 1966 The Ways of Paradox and Other Essays. Random House, New York, p 156-175

Quine WVO (1961) Reference and modality. In: From a logical point of view. Harper and Row, New York, pp 139-159

Romero C (2019) Modality is not explainable by essence. Philos Q 69:121-141

Wildman N (2018) Against the reduction of modality to essence. Synthese. https://doi.org/10.1007/ s11229-017-1667-6

Williamson T (2007) The philosophy of philosophy. Wiley-Blackwell, Malden

Witt JC (2011) Essence and existence. In: Lagerlund H (ed) Encyclopedia of medieval philosophy. Springer, Dordrecht. https://doi.org/10.1007/978-1-4020-9729-4_157

Publisher's Note Springer Nature remains neutral with regard to jurisdictional claims in published maps and institutional affiliations.

\section{Affiliations}

\section{Harold W. Noonan ${ }^{1}$}

$\triangle$ Harold W. Noonan

Harold.noonan@nottingham.ac.uk

1 Department of Philosophy, University of Nottingham, University Park, Nottingham NG7 2RD, UK 